\title{
A Teoria Protoindustrial: origem, desenvolvimento e atualidade
}

\author{
Felipe Lima de Medeiros ${ }^{1}$ \\ Luiz Carlos Delorme Prado ${ }^{2}$
}

\section{Resumo}

Antes da Revolução Industrial propriamente dita, a indústria estava em expansão na Europa tanto em produto total como em mão de obra ocupada. Essa expansão ocorreu sob um regime produtivo bastante diferente do que viria a caracterizar a Revolução Industrial. Franklin Mendels batizou esse regime de protoindústria e defendeu que seu desenvolvimento foi um catalisador para a industrialização moderna posterior. Mendels criou assim uma linha de pesquisa que foi desenvolvida e criticada por diversos autores. Este trabalho retoma a teoria protoindustrial e seus principais desenvolvimentos assim como reavalia suas críticas e seu poder heurístico atual.

\section{Palavras-Chave}

Protoindústria. Industrialização. Indústria rural. Revolução Industrial. Putting-out System.

\begin{abstract}
Before the Industrial Revolution itself, the industry was expanding in Europe both in total product as occupied labor. This expansion took place under a very different production regime that would characterize the Industrial Revolution. Franklin Mendels called this regime as proto-industry and argued that its development was a catalyst for the subsequent modern industrialization. Mendels thus created a line of research that has been developed and criticized by several authors. This work resumes protoindustrial theory and its major developments as well as reevaluates its criticism and its current heuristic power.
\end{abstract}

\section{Keywords}

Proto-industry. Industrialization. Rural Industry. Industrial Revolution. Putting-out System.

\section{JEL Classification}

N13. N33. O14

1 Supervisor Geral de Pesquisas - Instituto Brasileiro de Economia e Estatística (IBGE) Endereço: Rua Equador, 558 - $4^{\circ}$ andar - Santo Cristo - Rio de Janeiro/RJ - Brasil - CEP: 20220-410 E-mail: felipe.lima_9@hotmail.com - https://orcid.org/0000-0002-8571-8032.

2 Professor - Universidade Federal do Rio de Janeiro (UFRJ) - Endereço: Avenida Pasteur, 250 Urca - Rio de Janeiro/RJ - Brasil - CEP 22290-240 - E-mail: 1cdprado@gmail.com https://orcid.org/0000-0001-8269-2853.

Recebido: 23/10/2017. Aceite: 03/05/2018.

(c) (i) (\$) Esta obra está licenciada com uma Licença Creative Commons Atribuição-Não Comercial 4.0 Internacional. 


\section{Introdução}

Indústria doméstica é um tema antigo, há muitas referências na literatura econômica desde o século XIX. Marx (1887, Capítulo 30), por exemplo, distinguiu, embora sem nomeá-las, dois tipos de indústria doméstica: (i) uma de indústria doméstica "original" que se centrava na produção para autoconsumo e (ii) uma indústria doméstica "auxiliar" que tinha como finalidade suprir as grandes fábricas (large manufactories) capitalistas com produtos semiacabados. Embora Marx não tenha dado muita importância analítica a essa segunda definição, ela se aproxima do conceito de protoindústria. A Escola Histórica de Economia Política Alemã usou o conceito de indústria familiar (household Industry) como uma categoria histórica que caracterizava uma fase de transição entre a produção industrial para autoconsumo e o sistema de fábrica (factory). ${ }^{1}$ A expansão dessa indústria familiar voltada para o mercado estaria conectada com a expansão da exportação no período pré-moderno e a incapacidade das guildas de atender essa demanda. Um refinamento da teoria dentro da escola histórica alemã levou a denominar essa produção familiar para mercado não como uma fase de transição, mas como um momento específico distinto tanto da produção artesanal (handicraft) quanto da produção fabril (factory). A distinção específica dessa indústria familiar seria a presença de duas classes assimétricas: O pequeno produtor rural e os comerciantes que dominavam a produção. (Gullickson 1983, Kriedt, Medick e Schlumbohm 1981).

$\mathrm{Na}$ vasta literatura de história econômica publicada no século XX, o debate sobre o papel da indústria doméstica teve uma presença importante. Em especial, houve intensa controvérsia sobre o papel do putting out system na transição do feudalismo para o capitalismo. Nesse debate, algumas obras de autores marxistas tiveram grande repercussão. ${ }^{2}$ Esses foram os primeiros a apontar que o comerciante (put-outer) organizava os inputs e os outputs, fornecendo matéria-prima e comprando o produto acabado, mas não tinha o controle do processo produtivo. Esse sistema era superior à produção artesanal urbana porque empregavam trabalhadores agrícolas part-time e não estava sujeito às regulações das guildas. Mas também tinha seus problemas: o controle de qualidade era difícil, muitas vezes os trabalhadores tinham capacidade de lesar o comerciante desviando uma

1 Esta é a interpretação proposta por Gustav Schmoller \& por Karl Bücher. Para uma descrição da visão empírica de história econômica desses autores ver Usher (1949), ver especialmente a página 138.

2 Na Grã-Bretanha participaram do debate Maurice Dobb, Paulo Sweezy, Christopher Hill, Eric Hobsbawm, entre outros. Uma coletânea com os principais artigos sobre o debate marxista na década de 1950 foi publicado no Brasil pela Paz e Terra. Ver Sweezy e outros (1973). 
parte da matéria prima e, ainda, esses - quando conseguiam aumentar os ganhos de seu trabalho - tendiam a preferir o lazer a aumentar as horas trabalhadas. ${ }^{3} \mathrm{O}$ tema também foi discutido por vários críticos da história econômica marxista como Landes e Mokyr. ${ }^{4}$

O debate sobre indústria doméstica toma uma nova dimensão com a publicação do artigo de Mendels (1972), que sistematizou o conceito de protoindústria. Esse artigo seminal abriu uma grande polêmica sobre a relação entre a indústria artesanal, protoindústria e sistema de fábrica. Esse debate qualificava a relação entre produção industrial - produzida pelo sistema de fábrica - um fenômeno do final do século XVIII e do século XIX - e a produção artesanal e doméstica de produtos manufaturados. Como o próprio Mendels ressaltou, citando Hicks; "A Revolução Industrial foi o início da indústria moderna e não o início da indústria". ${ }^{5}$ A vasta literatura monográfica sobre as diversas regiões da Europa Ocidental, mostra que em muitas regiões do que hoje é a Alemanha, a França, Holanda e Inglaterra havia uma grande produção realizada por famílias camponesas de produtos manufaturados sob encomenda de comerciantes urbanos.

A teoria protoindustrial, embora originalmente formulada para a experiência europeia, apresentou um conjunto de proposições analíticas que podem ser usadas para analisar a indústria doméstica em outras sociedades. Protoindustrialização pode ser observada nos casos de economias mercantis como a Chinesa, no século XVIII, como a do Império Otomano, no século XIX, ou mesmo em economias coloniais, como o México e o Brasil do século XVIII. ${ }^{6}$ Este artigo tem por objetivo apresentar o debate recente sobre a protoindústria e seu papel para as origens da industrialização, discutindo a atualidade do conceito e suas limitações para seu uso além das fronteiras das transformações econômicas da sociedade europeia. ${ }^{7} \mathrm{Na}$ Europa, como no resto do mundo, a protoindústria não levou necessaria-

3 Ver o trabalho clássico de Dobb (1967). Sobre processo de trabalho nas fábricas são referências fundamentais Braverman (1974), Pollard (1965) e Stephen Marglin (1974)

4 Ver, por exemplo, a crítica de Landes (1986) ao artigo de Marglin (1974). Ver, também, o livro clássico de Landes (1969) sobre a industrialização europeia e Mokyr (1976)

5 Mendels $(1972,241)$ O texto citado está em Hicks $(1969,141)$

6 Para protoindustrialização no México, ver Grijalva (1989). Para uma análise comparativa de experiência de protoindustrialização em cidade brasileira e norte-americana, ver Dantas (2008). Para Protoindustrialização na China ver o livro de Bin Wong (1990) e Medeiros (2018). Para protoindustrialização no Império Otomano ver Islamoglu-Inan (1994)

7 Nas últimas décadas, o debate sobre as origens da Revolução Industrial continua dando origem a uma produção intelectual vasta, instigante e de alta qualidade. Não é, no entanto, objetivo deste artigo analisar essa literatura. Em especial, as obras recentes de Allen (2011), Goldstone (2008), Mokyr (2017) são boas referências dessa nova literatura. Para uma excelente sistematização dos debates sobre a Revolução Industrial, ver O`Brien (2010). 
mente à industrialização. Com o avanço da Revolução Industrial, a expansão do sistema de fábrica levou ao desaparecimento da protoindústria em várias regióes periféricas na Europa e fora dela. Por outro lado, o próprio desenvolvimento do sistema de fábrica na Europa Ocidental está associado a regiões onde previamente havia produção protoindustrial, pelo menos no setor têxtil, um dos mais importantes para a Revolução Industrial. Nesse sentido, o estudo das condições do aparecimento da protoindústria e de sua decadência iluminam as tentativas bem-sucedidas de desenvolvimento de determinadas regiões na Europa e fora dela - assim como a prematura "desindustrialização" com a decadência da indústria rural na periferia europeia (como no Império Otomano), em colônias europeias (Índia Britânica) e, até mesmo, em outras regiões periféricas do mundo, como na América Latina.

Em muitas regiões da Europa a produção industrial para mercado era crescente em valor total, valor relativo e mão de obra ocupada antes da Revolução Industrial. Esse fenômeno esteve relacionado à mudança da produção industrial no mercado de produtos têxteis de bens de luxo para bens de massa. Nessa transição a seda foi substituída pela lã como insumo básico da indústria. A lã era mais simples de ser trabalhada, exigia menos conhecimentos técnicos e destinava-se ao relativamente extenso mercado de produtos têxteis europeu. A Inglaterra se beneficiou especialmente dessa transição por dispor de grande oferta de lã. ${ }^{8}$ (Landes 1969, Mendels 1972, Gullickson 1983, Levine 1977, Kriedt, Medick e Schlumbohm 1981)

A tese de Mendels, posteriormente aprimorada por seus seguidores, é que esse aumento da produção de mercadorias manufaturadas pelas famílias em distritos rurais para posterior comercialização viria a impulsionar a Revolução Industrial. O conceito de protoindústria cumpriria o papel de explicar a particularidade dessa produção doméstica para o mercado e, ainda, mostrar a forte correlação entre os distritos em que se observava a existência de protoindústria e o surgimento no século posterior do sistema de fábrica.

A fábrica moderna é caracterizada pela existência de quatro elementos: (i) produção centralizada, (ii) uso de mão de obra assalariada, (iii) controle da produção e dos meios de produção pelo capitalista e (iv) uso significativo de capital fixo na forma de máquinas e equipamentos. Antes do século

8 O algodão só será o principal produto têxtil de exportação na Inglaterra no início do século XIX. (Cameron 1985) 
XIX produção industrial não esteve predominantemente conectada com nenhuma dessas características ${ }^{9}$ Braudel (2009) ressaltou o fato de a palavra "indústria" ter sido totalmente apropriada pelo conceito moderno de fábrica, enquanto na maior parte do tempo significou simplesmente "trabalho, atividade, habilidade" associando-se à ideia de "produção artesanal". Ironicamente, para retornarmos a esse sentido antigo, que perdurou por muitos séculos, temos que usar prefixos como pré-indústria ou protoindústria.

Essa necessária ruptura etimológica é uma indicação da grande transformação que foi a Revolução Industrial. Antes da indústria moderna a maior parte da produção industrial acontecia no campo e era voltada para o autoconsumo. A produção industrial para mercado dava-se nas cidades. Com o alargamento das relações de mercado, os produtos industriais rurais passaram a ser comercializados em mercados locais. A protoindústria surgiu numa fase posterior, quando os produtos industriais rurais passam a ser vendidos não apenas em mercados locais, mas também em mercados regionais e internacionais (Braudel 2009; Kriedt, Medick e Schlumbohm 1981). A produção da protoindústria era majoritariamente de produtos têxteis, mas eram fabricados também muitos outros produtos, como luvas, produtos de palha, de vidro e trabalhos em couro e metal. (Houston \& Snell 2010, Hobsbawm 1977).

A protoindústria foi definida por Mendels como uma indústria familiar, localizada na região rural, com quase nenhum capital fixo, em que o produto é vendido para um mercado não local. De modo geral, os produtores nessa indústria não tinham a capacidade de levar o produto até os mercados finais por falta de capital, tempo ou conhecimento. Esse sistema de produção dependia então de comerciantes que compravam o produto e revendiam em mercados distantes. Os comerciantes lucravam unicamente com a circulação de mercadorias não tendo controle direto sobre a produção. ${ }^{10}$ Esse processo criava um sistema de produção e distribuição que Braudel $(2009,201)$ chamou de "capitalismo em casa alheia". O trabalhador da protoindústria era, de modo geral, um agricultor que produzia para sua subsistência e não conseguia se alimentar apenas de sua produção

9 Indústria é um conceito que se aplica a produção de mercadorias não agrícolas. Produtos industriais podem ser obtido através de várias formas de organização da produção. Indústria de subsistência, protoindústria, manufatura centralizada e sistema de fábrica são diferentes formas de organização da produção - todas produzem, ao final, produtos industriais.

10 Marx não considerava capitalista a dinâmica produtiva protoindustrial, pois para esse autor é através do controle da produção e não da circulação de mercadorias que o capitalista se apropria da mais-valia. Marx (1887 p. 507) 
agrícola. Para poder sobreviver esses agricultores se dedicavam ao trabalho industrial especialmente no período entressafras quando havia pouco trabalho agrícola que pudesse ser feito (Mendels 1972, Kriedt, Medick e Schlumbohm 1981).

Uma prática comum era os comerciantes contratarem intermediários ( $m i$ ddlemen) da região para fazer o intercâmbio entre eles e os produtores facilitando a supervisão da produção e a troca entre matéria-prima e produtos finais. Frequentemente o comerciante urbano também adiantava a matéria-prima para esses pequenos produtores rurais. Isso ocorria porque o produtor rural raramente tinha capital para comprar os insumos necessários, especialmente quando esses vinham de mercados distantes, como era o caso do algodão. ${ }^{11}$ Com esse adiantamento, os comerciantes passaram a tentar controlar o processo produtivo exigindo prazos, estabelecendo metas de qualidade e preço do produto final. Todavia, o controle do comerciante era limitado, já que esse não podia vigiar diretamente a produção que era controlada pelo pequeno produtor rural, que era o dono dos meios de produção e, ainda, trabalhava em sua própria casa (Mendels 1972; Kriedt, Medick e Schlumbohm 1981).

Esse processo em que o comerciante adiantava o insumo e comprava o produto industrial ficou conhecido como putting-out system.$^{12}$ A protoindústria seria então financiada pelo capital urbano dos comerciantes que, trabalhando através do putting-out system, integravam pequenos produtores domésticos a mercados regionais e internacionais (Mendels 1972; Kriedt, Medick e Schlumbohm 1981; Houston \& Snell 2010). Uma vantagem para os trabalhadores no putting-out system era poder morar no campo com suas famílias produzindo manufaturas em casa e controlando o processo produtivo, o que aumentava muito sua qualidade de vida, entre outros motivos, por não necessitar morar nos centros urbanos. As cidades europeias foram chamadas de armadilhas da morte (death traps) dada a alta mortalidade que a falta de saneamento gerava. As cidades também eram vítimas de cercos, saques e outras vicissitudes que aumentavam a mortalidade. (Mokyr e Voth 2010, Mendels 1972)

Este artigo é composto, além da introdução e conclusão, por 3 seções. A seção 2 discute a relação entre protoindústria e indústria moderna.

${ }^{11}$ Hudson (2004) defende que quanto maior o turnover do processo produtivo mais comum seria essa prática. Assim em regiões que produziam produtos de melhor qualidade como West Country na Inglaterra.

${ }^{12}$ Verlagssystem em alemão no original. (Braudel 2009) 
A seção 3 trata do surgimento da protoindústria. A seção 4 tratará da crítica ao conceito de protoindústria e a sua relevância na historiografia recente. Finalmente, a conclusão retomará os pontos principais apresentados.

\section{O Papel da Protoindústria na Industrialização Moderna}

Em que medida a existência de distritos rurais onde camponeses especializaram-se na produção artesanal para o mercado foi relevante para o surgimento da Revolução Industrial na Europa? O trabalho seminal de Mendels analisou detidamente essa questão. Esse autor distinguiu na protoindustrialização quatro fatores que poderiam alavancar uma industrialização moderna.

Primeiro, os comerciantes, através desse processo, acumulavam capital que depois poderia ser usado no estabelecimento de fábricas modernas que precisavam de maior capital fixo e empregados permanentes que não estivessem à mercê da sazonalidade agrícola. ${ }^{13}$ Segundo, o processo fornecia capacidade empreendedora e conexões de mercado para a classe mercantil. Terceiro, a produção em massa para o mercado fornecia conhecimento técnico do processo produtivo para trabalhadores que posteriormente seriam empregados nas fábricas e manufaturas centralizadas. No início da industrialização os conhecimentos técnicos para a modernização da indústria têxtil eram simples, o que levava a que a mão de obra originária da protoindústria, que já tinha alguma experiência nesse tipo de atividade, torna a ser uma força de trabalho versátil e muito importante. ${ }^{14}$ Quarto, a protoindústria fazia os produtores se especializarem na produção manufatureira passando a consumir produtos agrícolas comprados no mercado. Esse aumento de demanda agrícola via mercado incentivava por sua vez a especialização em agricultura comercial em outras regiões (Mendels 1972, Hobsbawm 1977).

${ }^{13}$ Chapman identificou que 12 das 43 empresas líderes de fiação no norte da Inglaterra foram estabelecidos pelo capital de comerciantes na virada do século XVIII para o XIX o que equivale a $28 \%$ do total. Além disso, o capital mercantil também foi importante para a formação de capital na indústria de algodão nos Midlands, importante centro produtivo no período, e na Escócia (Chapman 1970).

${ }^{14}$ Hobsbawm observou que "Felizmente poucos refinamentos intelectuais foram necessários para se fazer a revolução industrial. Suas invenções técnicas foram bastante modestas, e sob hipótese alguma estavam além dos limites de artesãos que trabalhavam em suas oficinas ou das capacidades construtivas dos carpinteiros, moleiros e serralheiros: a lançadeira, o tear, a fiandeira automática." (Hobsbawm 1977, 62). 
A acumulação desses elementos facilitaria um "processo autônomo" de revolução industrial como ocorreu na Inglaterra. E ainda, mesmo em países retardatários, quanto mais desenvolvida estivesse a protoindústria mais fácil seria o desencadeamento de uma revolução industrial. Mendels ressaltou que onde a protoindústria estava avançada, gerando grande quantidade de emprego, os governos tinham também mais incentivo a reagir ao desafio inglês da industrialização. Onde os fatores citados eram insuficientes para gerar a "industrialização autônoma" moderna, a concorrência com a Inglaterra começou a gerar um processo de desindustrialização e desemprego com grande insatisfação popular. Os governos tendiam então a responder à industrialização da Inglaterra, para evitar o desemprego em massa decorrente de uma "desprotoindustrialização" (Mendels 1972).

Mendels apontou que em uma série de regiões, como Alsácia e Renânia, localizadas na França e Alemanha respectivamente, onde a protoindústria se concentrava, ocorreram mudanças econômicas que levaram à formação de modernos centros industriais. Por outro lado, regiões sem protoindústria só se transformaram em centros industriais modernos em decorrência de outros fatores, tais como, matéria prima abundante ou novas fontes de energia disponíveis, como, por exemplo, na Lorraine, França ou Krivoi Rog na Ucrânia. (Mendels 1972, 245-246) Mendels e os teóricos posteriores da teoria protoindustrial enfatizaram que esse processo não implica que a protoindústria fosse condição suficiente para a Revolução Industrial. A maioria das regiões protoindustriais se desindustrializaram frente a competição com a Inglaterra. ${ }^{15}$ Mendels apontou que condições além da protoindústria eram importantes para que a "primeira fase da industrialização" passasse para a indústria moderna. Mendels ressaltou a importância do acesso à matéria prima e a novas fontes de energia, mas escreveu que o determinante seria “acima de tudo a estrutura sociopolítica." (Mendels 1972, 246).

O trabalho original de Mendels sobre protoindústria tem muitas limitações. Uma delas foi não detalhar o que seria essa "estrutura sociopolítica", embora, de acordo com suas próprias palavras, esta era uma condição fundamental. Muitas dessas limitações foram enfrentadas por seus seguidores, em especial, no instigante trabalho de Peter Kiedte, Hans Medick e Jürgen Schlumbohm (doravante KMS) do instituto de história alemã Max-Planck. ${ }^{16}$ Esses autores avançaram na pesquisa original de Mendels

${ }^{15} \mathrm{O}$ autor apontou como casos de desprotoindustrialização Ulster na Irlanda, Silésia na Polônia e Bretanha na França.

${ }^{16}$ Esses autores deram imensa contribuição para o debate sobre protoindústria através do livro Industrialization before Industrialization de 1981. 
especificando muitos pontos que o autor tinha deixado vagos, assim como trazendo novos temas para a discussão sobre protoindústria.

Em particular observam-se três contribuições centrais desses autores: (i) A nova interpretação de significado da protoindústria, (ii) a especificação sobre as causas da protoindústria e (iii) novos fatores pelos quais a protoindústria teria contribuído para a industrialização moderna. Para Mendels, a protoindústria era a "primeira fase da industrialização". KMS (1981) vão usar outra definição. Para eles, a protoindústria será uma das principais forças na "segunda fase da transição do feudalismo para capitalismo". ${ }^{17}$ Segundo KMS, a conjunção da protoindústria com outros fatores desenvolveu uma dinâmica que, no final do XVIII, permitiu às áreas mais avançadas e mais "industrializadas" romper o ciclo malthusiano de crescimento populacional, queda de renda per capita e crises de comida.

KMS voltaram aos primórdios da protoindústria para desenvolver sua teoria. Segundo os autores, a tendência à protoindustrialização foi reforçada pela "primeira fase da transição do feudalismo para o capitalismo" decorrente da alteração na maneira de cobrar tributos. No sistema feudal, os impostos eram cobrados em serviços e espécie, o que reduzia a circulação monetária e o desenvolvimento de mercados. Ainda na Alta Idade Média, séculos XI ao XIII, esses impostos começaram a ser cobrados em dinheiro em alguns lugares da Europa. As precondições para essa mudança foram duas: (i) o aumento populacional e (ii) o aumento da produtividade agrícola. Essas levaram a integração e crescimento das cidades, aumento das relações de mercado no interior, ocupação de terras virgens e mudanças nas relações de classe. Esse processo foi bem mais rápido e profundo na Europa Ocidental, em comparação à Europa Oriental. Nesse contexto, os custos de transação para supervisionar os serviços cobrados como tributos passaram a ser muito altos, sendo economicamente vantajoso cobrar impostos em moeda. Os impostos em moeda facilitaram e propagaram o desenvolvimento da protoindústria e da agricultura comercial como formas de conseguir os recursos monetários para pagar o imposto, enquanto os impostos em produtos e serviços inibiam a produção para o mercado, pois os produtores tinham a expectativa de que quanto mais produzissem mais seriam explorados.

17 Outra força dirigente na segunda fase da transição do feudalismo para capitalismo seriam mudanças no setor agrário decorrentes das influências da protoindústria e da própria dinâmica interna do setor agrário. (KMS 1981) 
Foi ainda na primeira fase da transição do feudalismo para o capitalismo que emergiu a divisão de trabalho entre cidade e campo. A cidade fazia produtos industriais e o campo fazia produtos agrícolas para mercado. ${ }^{18}$ Com o tempo, começou a ocorrer um grande aumento da demanda dos produtos industriais. Essa demanda era interna e externa vinda do comércio intraeuropeu e especialmente das colônias.

As cidades, embora já fossem especializadas na produção de manufaturas e produtos artesanais para o mercado, foram incapazes de absorver esse aumento de demanda industrial por três motivos. Primeiro, as cidades estavam sobre a influência das guildas, que tinham como objetivo garantir a qualidade de vida dos seus membros. Com o poder de monopólio, as guildas limitavam a produção, controlavam a competição por preço ou qualidade, impediam novos produtos e técnicas que pudessem prejudicar seus membros e limitavam o acesso aos mercados. Isso não quer dizer que os trabalhadores rurais protoindustriais não tentaram se organizar para resistir à exploração ou aos métodos produtivos que mudassem ou prejudicassem seu estilo de vida, mas a capacidade de resistência e organização das guildas nas cidades era muito maior do que a de camponeses dispersos (Landes 1969, KMS 1981). A produção protoindustrial ajudou a minar o privilégio das guildas urbanas que não tinham como concorrer ou manter o controle produtivo frente a grande oferta de produtos manufaturados vindos do campo. As guildas tentaram resistir em algumas ocasiões exigindo regulamentação da produção industrial rural, mas não tiveram muito sucesso. ${ }^{19}$

O segundo motivo para a baixa elasticidade da oferta de produtos industriais pelas cidades europeias até o século XVIII foi a relativa escassez de mão de obra nas cidades. Para atender o aumento da demanda de produtos industriais, sem um grande aumento de produtividade, era necessária mais mão de obra, a qual só podia ser encontrada no campo, onde estava a maior parte da população. Em nenhum país a população urbana no início do século XVIII chegava a $40 \%$ do total. ${ }^{20}$

${ }^{18}$ Observe-se que, nessa fase, enquanto a produção industrial para mercado se concentrava nas cidades a produção industrial para autoconsumo, que era muito maior, continuava concentrada na região rural.

${ }^{19}$ Ver Medels (1972), Jeannin (1980) e KMS (1981). David Levine (1977) cita uma importante disputa legal que a Worshipful Company of Framework Knitters, guilda controlada pela oligarquia londrina, que desde 1663 controlava a produção têxtil na região, teve com camiseiros protoindustriais da região rural de Nottingham e Cartwright. No final os camiseiros tiveram vitória legal, o que abriu portas para o fim do monopólio das guildas na região.

20 População urbana para alguns países europeus: Holanda 39\%, Bélgica 31\%, Itália 23\%, Espanha 20\%, Inglaterra 17\%, França 12\%, Alemanha 8\%, Polônia 4\%. (Allen 2000) 
Terceiro motivo, o campo oferecia ainda diversas vantagens de custos frente as cidades. Como o trabalhador da protoindústria garantia parte da sua subsistência através da agricultura, sua remuneração podia ser inferior ao nível de subsistência. No campo havia menos impostos, algumas matérias primas eram mais baratas e a comida também era mais barata. Hudson (2004) defende, ainda, que políticas de alívio a pobreza poderiam reduzir os custos do trabalho no campo.

Temos então dois importantes fatores prévios para a expansão da protoindústria: inicialmente uma mudança na forma de taxação governamental e posteriormente a necessidade de flexibilizar a oferta de produtos em virtude da demanda interna e externa expandida. A flexibilização da oferta por sua vez seria mais fácil no campo que na cidade por conta das guildas, diferenças de custos e disponibilidade de mão de obra. Nesse segundo momento é que se daria a ruralização da produção industrial para o mercado e a grande expansão da protoindústria. Observe-se que a produção industrial rural já era significativa antes disso, mas estava muito restrita ao autoconsumo ou ao consumo local - estando fora, portanto, do conceito de protoindústria.

Mendels, ao contrário de KMS, não ofereceu uma teoria clara para o início da protoindustrialização, sendo essa uma das limitações de sua obra. Mendels escreve que "não há uma resposta fácil" e sugere rapidamente e sem nenhum aprofundamento três interpretações: primeira, aumento exógeno do crescimento populacional, que Jan de Vries teria apontando como causa da protoindustrialização nos Países Baixos (1970); segunda, redução do crescimento populacional com aumento de produtividade agrícola, que teria levado a captura dos mercados agrícolas por agricultores de alta produtividade, empurrando outros agricultores para o mercado industrial, teoria defendida por Eric Jones (1968); e a terceira interpretação seria que o impulso pela via da demanda dos mercados coloniais teria incentivado a especialização das regiões dependendo de condições geográficas e institucionais, essa última interpretação é atribuída a Eric Hobsbawm (1969). (Mendels 1972; KMS 1981).

A abordagem de KMS apresenta assim uma interpretação mais clara das causas da protoindustrialização. Além disso, apresenta novas razões para a relação entre a protoindústria e a indústria moderna. Para KMS, ao atender a demanda colonial e, portanto, aumentar a elasticidade da oferta industrial, a protoindústria teria permitido a formação dos Sistemas Mundo 
(World Systems) como teorizado por Wallerstein (2011). Os países da periferia se especializaram no fornecimento de matéria prima usando trabalho escravo ou servil com baixa remuneração, enquanto a maior parte do lucro era apropriada nos países do centro que produziam manufaturas e usavam trabalho livre. Esse sistema de trocas desiguais estabeleceu-se antes do surgimento da indústria moderna e reforçou a dicotomia centro-periferia e a divisão internacional do trabalho. Essa inter-relação teria permitido o desenvolvimento acumulativo do centro enquanto aprisionava a periferia num ciclo de atraso e subdesenvolvimento.

Outro novo fator pelo qual a protoindústria ajudaria no processo de industrialização moderno foi a relação conflituosa entre a protoindústria e o sistema feudal. Nesse ponto, KMS retornam à importância da "estrutura sociopolítica" que Mendels havia considerado essencial para o desenvolvimento da indústria, embora não tenha desenvolvido o tema. Para KMS, o monopólio sobre a força de trabalho exercido no sistema feudal impediria que uma massa de trabalhadores se voltasse para a protoindústria. Os costumes e obrigações feudais eram barreiras para o desenvolvimento da indústria rural.

Os senhores feudais também impediam que os camponeses perdessem as suas terras em caso de quebras de safra, pois tinham interesse em mantê-los nas terras e não liberar essa força de trabalho para outras atividades. Mesmo que fosse desejo dos camponeses dividir a propriedade, os senhores feudais ou a comunidade de aldeões poderiam insistir na indivisibilidade da terra, suprimindo a emergência de um mercado de terras e controlando a mobilidade dos aldeões. Sob o regime feudal podia haver, ainda, controle judicial de casamentos ou do consentimento para se casar, o que restringia o aumento da população. $O$ feudalismo reduzia assim o crescimento populacional e a diferenciação entre os camponeses em produtores protoindustriais e agricultores.

Onde os laços feudais eram mais fracos, a protoindústria tinha condições melhores de se estabelecer, e uma vez que isso acontecia, ela começava a enfraquecer ainda mais o sistema senhorial (manorial system), pois gerava uma renda que estava fora da propriedade da terra e das relações de poder que eram estabelecidas através da terra. A produção manufatureira necessitava pouco mais que um teto e matéria prima para ser executada. As comunidades, os lordes e as relações de poder intrafamiliares perdiam força 
com a emergência da indústria rural, pois sempre era possível escapar da dependência da terra e da herança através da produção protoindustrial. ${ }^{21}$

O desenvolvimento da protoindústria, assim como da indústria moderna, dependia e implicava o enfraquecimento de relações de produção feudais. Enquanto a indústria moderna é urbana e precisa de mobilidade do trabalho, o feudalismo era rural e precisava de camponeses fixos a terra para citar apenas uma das contradições. Nas regiões em que a protoindústria enfraquecia os laços feudais eram também criadas condições para que futuramente uma industrialização moderna pudesse se desenvolver. Isso não quer dizer que as condições de produção da protoindústria e da indústria moderna sejam as mesmas. Lembremos que na protoindústria o controle da produção ainda era dos trabalhadores e havia pouca inovação técnica. Os trabalhadores tinham vários motivos para se opor a inovações técnicas como: alto custo de capital, receio de que a inovação resultasse em desemprego, resistência aos custos de patente e ao aluguel de máquinas que colocassem seu trabalho mais à mercê dos desejos dos empreendedores (KMS 1981). Além disso, os baixos custos do trabalho no campo decorrentes da grande oferta de mão de obra e da capacidade do mercador de negociar os salários individualmente, devido à desunião dos camponeses, desincentivavam o investimento em capital pelo comerciante (Levine 1977). Nessas condições, não compensava substituir mão de obra barata por capital. Esse último ponto não foi colocado por KMS que consideram a falta de controle direto da produção o motivo principal para a ausência de investimento por parte dos comerciantes.

Para Landes (1969), o principal motivo para a ausência do investimento seria a incerteza sobre mercados distantes. Como o comércio protoindustrial era muitas vezes interrompido por guerras ou por ausência temporária de demanda, era desvantajoso imobilizar capital. Somente com a redução das guerras e a maior integração de mercado valeria a pena investir, nessas condições o sistema de fábrica se mostrava superior à protoindústria.

Por outro lado, KMS alegam que os pequenos produtores industriais não tinham, de modo geral, a mentalidade de um empresário capitalista e não procuravam acumular capital ou investir. A prioridade era garantir a subsistência da família e caso a renda subisse, a tendência era que esses

${ }^{21}$ Parece que foi nesse conflito com o feudalismo que KMS identificaram a "estrutura sociopolítica" que Mendels havia mencionado como determinante "acima de tudo" para o desenvolvimento da indústria moderna. Ao especificá-la, KMS fechariam essa lacuna na teoria. 
produtores procurassem reduzir a oferta de trabalho, gastando mais tempo com lazer. O excedente monetário que porventura esses pequenos produtores tivessem era gasto em consumo conspícuo e produtos de consumo imediato, como álcool e tabaco, que cumpriam um importante papel na socialização local desses grupos. ${ }^{22}$

No entanto, não foi simplesmente a falta de inovação técnica que levou a exaustão do modelo protoindustrial. Como a produção se expandia de forma extensiva - e não intensiva - os mercadores tinham que expandir a produção rural para áreas cada vez mais distantes e dispersas. Isso encarecia o custo de transporte e tornava cada vez mais difícil controlar a produção. Interrupções no processo produtivo, perda do produto e roubos por parte dos pequenos produtores tornaram-se cada vez mais comuns. Isso aumentava a necessidade de um sistema que centralizasse a produção e permitisse um controle efetivo do processo produtivo pelos empreendedores. O que levou a centralização do trabalho em grandes manufaturas que permitiram maior controle da mão de obra e ganhos de produtividade (Mendels 1972, KMS 1981).

Embora o avanço da protoindústria tenha criado condições favoráveis ao aparecimento do sistema de fábrica - essas condições podiam ser necessárias, mas certamente não eram suficientes. Um determinado nível de demanda, enfraquecimento das relações feudais, presença de capital mercantil e mão de obra disponível eram fatores necessários para que o processo protoindustrial chegasse ao seu limite de maneira que um sistema mais avançado de produção pudesse ser utilizado. Isso ocorreu de maneira "natural" somente na Inglaterra, enquanto os outros tiveram dificuldade para acompanhar o desafio inglês, o que levou muitas regiões à desindustrialização (Mendels 1972, KMS 1981). ${ }^{23}$

Viu-se, então, que a protoindústria teria levado a ruralização da produção de produtos industriais para a oferta no mercado. Essa ruralização foi consequência do expressivo aumento de demanda, graças a integração de mercados e das vantagens da protoindústria diante da indústria urbana das guildas. Entre essas vantagens foram mencionadas a disponibilidade

${ }^{22}$ Essa leitura sociológica é baseada no trabalho de A. V. Chayanov (1925), que dá ênfase ao fato de que os pequenos produtores não tinham uma mentalidade capitalista. Pode-se conjecturar que, pelo fato dos mercados que esses trabalhadores rurais tinham acesso serem pouco diversos, com poucos produtos, havia muito menos incentivo para acumular meios monetários. Entretanto, não se pode descartar que certamente havia grande diversidade regional.

${ }^{23}$ Inclusive regiões protoindustriais desindustrializaram-se dentro da própria Inglaterra (Coleman 1983). 
e o baixo custo da mão de obra, o custo dos insumos, e a ausência dos monopólios. Além disso, a protoindústria teria facilitado a emergência da indústria moderna por variados fatores: acúmulo de conhecimento e capital na mão dos comerciantes, acúmulo de conhecimento técnico, especialização regional, enfraquecimento das relações feudais e flexibilização da oferta de maneira que os mercados mundiais pudessem se integrar. $\mathrm{Na}$ próxima seção discutem-se os aspectos regionais do desenvolvimento da protoindústria.

\section{Fatores que Facilitavam o Surgimento da Protoindústria}

Se a protoindústria era tão central na dinâmica econômica ao produzir a maior parte dos produtos industriais para o mercado e foi tão importante para seu desdobramento ao facilitar o desenvolvimento industrial moderno, como visto na seção 1 , que circunstâncias, por sua vez, facilitariam seu desenvolvimento?

Diversos fatores foram apontados como indutores do desenvolvimento protoindustrial. A protoindústria precisava se difundir em regiões com populações compactas e razoavelmente acessíveis para que os mercados e comerciantes pudessem chegar aos produtores. Lugares de população muito esparsas faziam com que o custo de controlar, coordenar e transportar a produção ficasse proibitivo. Assim, uma das primeiras condições para a protoindústria foi que a dispersão produtiva e o custo de transporte não fossem muito altos (Mendels 1972, Gullickson 1983).

Era necessário também acesso aos grandes mercados. Quem garantia esse acesso eram os comerciantes das cidades que investiam na produção protoindustrial se utilizando de pessoas da região para organizar as transações locais. O capital mercantil urbano controlava a venda do produto e a disponibilidade de força de trabalho que dependia das condições no campo. Sem o encontro dos desejos da cidade com o campo, a protoindústria não poderia surgir. (Houston e Snell 1984, Gullickson 1983) O último ponto para a viabilização da protoindústria é que a taxa de retorno da produção manufatureira doméstica deveria ser maior que a taxa de retorno da agricultura, caso contrário, o pequeno agricultor intensificaria a produção agrícola e não se dedicaria à manufatura. Essa melhor remuneração da 
produção da indústria doméstica poderia decorrer de condições locais como, por exemplo, a presença de pequena propriedade camponesa. A pequena propriedade rural limitava a capacidade de produção agrícola. Isso incentivava a produção protoindustrial como alternativa de sustento e não unicamente pelo baixo retorno marginal do trabalho agrícola devido à baixa disponibilidade de terra, mas também pelo comportamento dos preços agrícolas, como se verá.

Tradicionalmente, o mercado agrícola operava oscilando com períodos de preços altos e baixos. O momento de baixa era logo após a colheita, quando o mercado estava relativamente saturado pela oferta. O momento de alta ocorria na entressafra, quando a oferta era menor. Quando o produtor agrícola dispunha de uma produção abaixo de determinado nível, ele não conseguia esperar o momento de alta no preço dos alimentos para vender, pois precisava garantir sua subsistência imediata. Esse produtor era então obrigado a vender assim que realizava a colheita no período de baixa dos preços. O pequeno produtor também seria obrigado a comprar alimentos quando o preço estivesse em alta, muitas vezes precisando se endividar. Isso diminuía as chances de o pequeno agricultor viver somente da terra, tendo que se voltar para a protoindústria para sobreviver (Gullickson 1983).

Alguns fenômenos facilitavam a existência de pequenas propriedades de terra, como aconteceu no caso da Bélgica. Mendels, em seu estudo sobre Flanders, no século XVIII, aponta que a maior parte da terra era arrendada. O aumento do preço da propriedade fundiária teria incentivado os senhores de terra a subdividi-las em áreas menores para ganhar mais com a renda da terra. Propriedades menores, por sua vez, reduziam a capacidade de sobrevivência das famílias que dependiam exclusivamente da agricultura. O crescimento populacional seria em parte responsável pelo aumento do preço das terras nessa região pelo lado da demanda, mas, para Mendels, o aumento de investimento no mercado de hipotecas por classes urbanas, como magistrados e comerciantes, seria a principal causa do encarecimento das terras em Flanders e da consequente fragmentação da propriedade. Nesse caso, o encarecimento da terra facilitou a protoindustrialização da região. 
O aumento populacional também contribuía para o surgimento de pequenas propriedades protoindustriais, pois o crescimento populacional levava a divisão da propriedade caso a herança fosse repartida. Mesmo que a propriedade não fosse dividida, graças a uma cultura de herança por primogenitura, o crescimento populacional levava a um uso mais intensivo da terra, o que, num ambiente de pouca inovação técnica ou tecnológica, gerava ganhos marginais decrescentes da terra aumentando o ganho relativo do trabalho industrial. Ou seja, mesmo sem divisão de terras, a protoindústria era incentivada pelo aumento populacional via queda da produtividade marginal agrícola. O aumento populacional, sem divisão de terras, também podia resultar em uma massa de desempregados sem-terra disposta a servir de força de trabalho para a produção protoindustrial como último recurso para sobrevivência. Assim, o aumento populacional sem aumento de produtividade agrícola ou abertura de novas terras aumentava a oferta de mão de obra para a protoindústria independente da forma de herança. ${ }^{24}$

A protoindústria também incentivava o aumento populacional, num processo de retroalimentação, ao fornecer uma fonte de renda que independia do aumento da produção agrícola. Um exemplo desse efeito foi apresentado por Mendels, que encontrou uma relação positiva entre o aumento do preço dos tecidos de linho com aumento da população para a região de Flanders (Mendels 1975). Uma referência para o estudo da correlação entre protoindústria e aumento populacional foi a importante obra de David Levine (1977). Este autor estudou um grupo de pequenas vilas na Inglaterra e concluiu que o principal mecanismo pelo qual a protoindústria afetava o crescimento populacional foi através da redução da idade de casamento e não queda da mortalidade. Os filhos dos pequenos produtores rurais se casavam mais cedo e ficavam mais tempo na casa dos pais em relação às famílias que viviam exclusivamente da agricultura, pois não dependiam da herança de uma propriedade para se sustentar e podiam ajudar na produção protoindustrial familiar. ${ }^{25}$

${ }^{24}$ Ver Mendels (1972). Sobre esse ponto, Joan Thirsk (1961) argumentou que a herança partilhada também incentivava o aumento populacional, já que os filhos sabiam que herdariam uma parte da terra e teriam assim sua subsistência garantida. Nesse sentido, Thirsk acredita que o aumento populacional catalisaria de maneira mais significativa a produção protoindustrial, caso esse aumento ocorresse sobre o regime de herança partilhada.

${ }^{25} \mathrm{O}$ casamento mais cedo não somente aumentava o período de fertilidade dos casais como antecipava o período reprodutivo, tendo duplo efeito sobre o crescimento populacional. 
Terras pouco férteis também podiam incentivar o crescimento protoindustrial, pois tinham um reduzido retorno marginal do trabalho na agricultura. De fato, KMS defenderam que a protoindústria se concentrava em terras impróprias para agricultura. ${ }^{26}$ Isso não quer dizer que regiões férteis em condições específicas não pudessem ser propícias à protoindústria. $\mathrm{O}$ Pays de Caux, localizado na Normandia, Norte da França, tinha uma terra bastante fértil, mas seu solo era difícil de ser arado, necessitando de equipamentos que os camponeses mais pobres não tinham condições de comprar ou alugar. Isso levou a um florescimento da produção protoindustrial, apesar de a região ter também uma significativa produção agrícola comercial em virtude da fertilidade do solo (Gullickson 1983).

Fatores políticos também podiam influenciar. David Levine aponta como em Bottesford, uma vila de Leicestershire, na Inglaterra, o duque local que dominava a terra simplesmente proibiu a produção doméstica de rendado, freando o desenvolvimento da protoindústria na região por fatores políticos e não geográficos ou demográficos. Aqui temos um claro exemplo de como instituições medievais podiam limitar a expansão da protoindústria (Levine 1977, 15).

Num caminho diverso, Eric Jones (1968) argumentou que a queda do crescimento populacional entre 1650 e 1750 na Europa Ocidental junto com o aumento da produtividade agrícola, graças ao cercamento dos campos, culturas forrageiras e pastos artificiais, ${ }^{27}$ teria levado a captura dos mercados urbanos por áreas mais produtivas, deixando os pequenos agricultores sem mercado para vender seus produtos agrícolas - o que os levou a se voltarem para a protoindústria e/ou pecuária.

A presença de desemprego agrícola também foi um dos fatores mais extensivamente tratados como causa de desenvolvimento protoindustrial. Esse desemprego podia ter duas fontes: Ser fruto do crescimento populacional ou da sazonalidade do trabalho agrícola. Nesse último caso, os desempregados apareciam em grande número onde havia intensa demanda sazonal por trabalho, característica presente em algumas regiões de agricultura comercial. Os períodos de plantio e colheita exigem muitas horas de esforço, mas no resto do ano há pouca necessidade de trabalho. Era justamente nesse período de baixa demanda de trabalho agrícola que o trabalhador

26 "It was no coincidence that the rural industries of Europe concentrated in barren mountain regions". (KMS 1981, 14)

27 Pastos artificiais são criados pelo homem que utilizam plantas próprias para o consumo de animais aumentando a produtividade pecuária. 
rural se dedicava à produção industrial. Certas colheitas eram particularmente dependentes de alta disponibilidade temporária de trabalho, como era o caso da plantação de batatas trazidas das Américas. Tal característica potencializava o fenômeno da sazonalidade agrícola e, consequentemente, da protoindustrialização. No caso de Flandres, na Bélgica, o surgimento de plantações com maior demanda sazonal por trabalho como batata e linhaça facilitaram o desenvolvimento da protoindústria. Um fato interessante é que quando o desemprego sazonal era o responsável pelo aumento da protoindústria, não havia necessidade da agricultura de subsistência ser predominante na região para que a protoindústria se desenvolvesse (Mendels 1972, Gullickson 1983).

Em síntese, a protoindústria dependia de capital mercantil, custos produtivos reduzidos, como acesso à transporte e dispersão produtiva não muito alta. Além disso, era necessário que a taxa de remuneração da produção industrial fosse maior do que a do trabalho agrícola. As quatro maneiras mais frequentes da maior remuneração relativa da indústria doméstica em relação à atividade agrícola são as seguintes:

(i) Dificuldade dos pequenos produtores conseguirem vender os produtos agrícolas a preços aceitáveis por conta da concorrência. (Jones 1968);

(ii) A presença de pequenas propriedades que impossibilitavam a viabilidade da produção atender a subsistência da família, o que, por sua vez, podia ser decorrência de crescimento populacional ou encarecimento das terras.

(iii) Baixa produtividade agrícola devido à qualidade do solo ou por haver alguma dificuldade produtiva que os pequenos produtores não tinham capital para superar, como no caso do Pays de Caux especificado acima.

(iv) Desemprego agrícola por conta de aumento populacional ou de alta sazonalidade no trabalho agrícola.

Foi visto, ainda, que outros motivos podem ser apontados para o não desenvolvimento protoindustrial, como o político, exemplificado no caso de Bottesford, e cultural ou social em decorrência de restrições feudais. Em 
seguida, na seção 4 , discutiremos as críticas à teoria protoindustrial e à atualidade do debate.

\section{Críticas e Poder Heurístico do Conceito de Protoindústria}

Protoindústria continua sendo um conceito controverso. A relevância dessa definição e seus limites têm sido submetido a escrutínio de vários historiadores, entre eles Coleman (1983), Houston e Snell (1984) e Ogilvie (1993; 2008). Essa literatura levou à reformulação de alguns aspectos da proposição original, mas as críticas ao uso desse conceito não são o suficiente poderosas para levar ao esgotamento dessa linha de pesquisa. Essa seção discutirá criticamente essa literatura e os impactos da mesma na teoria protoindustrial.

Essas críticas podem ser agrupadas nos seguintes conjuntos: Primeiro, a teoria seria incompleta por não considerar uma série de aspectos relevantes da realidade estudada (Coleman 1983, Houston e Snell 1984, Ogilvie 2008) ou imprecisa ao não definir com exatidão conceitos importantes (Coleman 1983, Cerman 1996, Ogilvie 2008;). Um segundo conjunto de críticas centram-se em premissas, correlações ou características observadas da teoria, tais como, salário em nível de subsistência (Coleman 1983), localização em regiões inférteis (Coleman 1983, Houston e Snell 1984), lógica do aumento populacional (Houston e Snell 1984) e mesmo a veracidade do efeito demográfico (Coleman 1983, Houston Snell 1984, Ogilvie 2008). Finalmente, um terceiro conjunto de críticas centra-se na relação entre protoindustrialização e indústria moderna. Nessa linha surgem argumentos de que os mercados externos não seriam relevantes para a Revolução Industrial (Ogilvie 2008, Houston e Snell 1984) ou de que a correlação entre protoindústria e desenvolvimento industrial seria fraca ou irrelevante (Coleman 1983, Houston e Snell 1984, Ogilvie 1993, 2008, Mokyr 1976, Allen 2002)

Sobre o primeiro conjunto, Coleman (1983) e Ogilvie (2008) escrevem que a teoria protoindustrial não considera padrões de herança, força de controle senhorial, disponibilidade de matéria-prima, proximidade com terras inférteis, tipo de agricultura, densidade populacional, entre outros; Ou seja, a teoria ignoraria uma série de fatores relevantes para o desenvol- 
vimento regional. Estranhamente todos os fatores citados, sem exceção, são trabalhados explicitamente por KMS. Difícil entender a finalidade desse tipo de crítica, uma vez que Coleman e Ogilvie analisaram, em profundidade, a teoria protoindustrial e não poderiam desconhecer que esses fatores foram apresentados e discutidos na literatura. Parece que, nesse caso, os críticos caíram na falácia do espantalho. ${ }^{28}$

Ogilvie (2008) acusa, ainda, a teoria protoindustrial de não mencionar a produção urbana e as manufaturas centralizadas, o que configuraria um "ponto fraco" da teoria. Coleman (1983) também critica esse ponto afirmando que a produção urbana e as manufaturas centralizadas seriam mais importantes para a "industrialização antes da industrialização" do que a protoindústria. De fato, KMS dedicam muito pouco do seu trabalho à produção manufatureira urbana e/ou centralizada, e Mendels nem as cita, mas KMS são específicos nos motivos que os levaram a se concentrar na indústria rural. KMS admitem que as manufaturas centralizadas dão lugar mais rapidamente a relações capitalistas do que à produção doméstica em massa, entretanto, reforçam que a produção rural foi mais importante em termos de número de trabalhadores e de valor criado. Além disso, a produção urbana era comumente ligada à produção rural, fazendo somente o acabamento do trabalho industrial rural antes de enviar o produto para o mercado final. Finalmente, segundo KMS, nem sempre é possível fazer uma distinção clara entre indústria rural e indústria urbana, pois os limites muitas vezes são tênues. A aglomeração protoindustrial podia gerar o que KMS chamaram de "quase cidades", regiões de significativa densidade populacional, sem guildas, o que dificulta a separação estrita urbano x rural.

Houston e Snell (1984) também falam que a competição interna entre as formas de produção industrial na Inglaterra é menosprezada pela teoria. Os autores defendem que o desenvolvimento da indústria moderna na Inglaterra levou a "desprotoindustrialização" do país. Isso não contradiz a teoria protoindustrial colocada por Mendels e KMS, que acreditam que a protoindustrialização cedeu espaço para a indústria moderna a partir de determinado ponto. $\mathrm{O}$ papel da protoindústria seria apenas catalisar a indústria moderna e não conviver com ela.

${ }^{28}$ Straw Man fallacy: consiste em transformar o argumento que está querendo se criticar de maneira que fique mais simples de refutar. Essa é uma falácia, uma vez que o argumento que está sendo criticado não é mais o original. Ver Lewinsky (2011) 
Um conjunto de autores centram suas críticas nas especificações da teoria. Ogilvie (2008), Cerman (1996) e Coleman (1983) criticaram a falta de especificação sobre o que seria uma região protoindustrial. Qual seria o tamanho ou o tipo de estrutura necessária para que a região fosse considerada protoindustrial? Em algumas regiões, a protoindústria se espalhava para além de uma região; em outras, constituía apenas uma pequena fração das comunidades envolvidas. Qual seria a participação necessária da protoindústria para que a região pudesse ser considerada protoindustrial? Nesse mesmo aspecto, Ogilvie (2008) criticou a falta de definição de quanto precisava ser exportado para ser considerada protoindústria ou o quão longe precisavam ser os mercados para que fossem considerados "não locais". ${ }^{29}$ Embora conceitos abstratos devam preferencialmente ser definidos de forma precisa, sua aplicação em um caso concreto abre sempre uma zona cinzenta, onde os limites não são tão claros. No caso, o que interessa é se o conceito indica atributos que são relevantes para entender processos históricos. Podemos também levantar questões sobre indefinições para outros debates na economia, como por exemplo: Quando exatamente um país passa a ser desenvolvido? Quando exatamente aconteceu a Revolução Industrial? Quando exatamente surgiu o capitalismo? O fato de não se saber exatamente o início do capitalismo ou fim do feudalismo não é uma crítica a sua existência ou importância - é apenas a constatação de que existe uma zona cinzenta entre esses dois objetos. Essa imprecisão não é um problema que convida ao abandono da teoria, mas sim ao seu aperfeiçoamento.

Sobre o segundo conjunto de críticas, Houston e Snell (1984) contestaram a proposição de que a protoindústria se concentraria em terrenos montanhosos e inférteis. Os autores constataram que a protoindústria se desenvolveu em todo o tipo de terreno, férteis e inférteis, vales e montanhas, onde tinha agricultura comercial e onde não tinha. Coleman (1983) também criticou esse ponto depois de analisar o caso inglês. Segundo o autor, vales com rios, terras altas com florestas e espaços amplos para pastoreio foram os principais terrenos usados na Inglaterra para a produção protoindustrial. Assim a protoindústria podia se desenvolver em espaços mais diversos do que a teoria previa. É verdade que KMS falam que é possível ter protoindústria em todo o tipo de terreno, mas afirmaram que quanto maior fosse a participação da protoindústria na produção total da região e quanto maior fosse sua participação na renda total, menos fértil tendia a

${ }^{29}$ Lembrando que protoindústria foi definida como uma produção industrial rural, familiar, com pouco capital fixo voltada para mercados não locais. 
ser a região protoindustrial. Ou seja, KMS defenderam sim uma relação inversa entre protoindústria e fertilidade do solo. Terreno montanhoso e infértil seria mais utilizado pela protoindústria e vales férteis seriam normalmente impróprios para esse tipo de produção, o que não se confirmou para casos mais amplos.

Entretanto, KMS, Gullickson (1983) e outros defensores da teoria protoindustrial defenderam que uma série de fatores podiam levar ao desenvolvimento da protoindústria em locais férteis, como visto na seção 2. Entre esses fatores foi apontado presença de terra fértil que precisasse de capital para ser arada ou a presença de propriedades diminutas que impedissem o sustento através somente da agricultura.

Houston e Snell (1984) fazem também uma estranha crítica à lógica demográfica da teoria protoindustrial: A protoindústria levaria ao aumento populacional e à expansão de um sistema que não beneficiava o uso de mais tecnologia. Isso levaria a uma estagnação com população crescente. Por outro lado, o aumento populacional, segundo a teoria protoindustrial, beneficiava o crescimento da protoindústria por conta da fragmentação de terras, como visto na seção 2. Para Houston e Snell isso seria uma contradição, pois o aumento populacional tanto incentivava quanto impunha limites à protoindustrialização. Houston e Snell parecem não ter atentado para o argumento de KMS. Não é propriamente o aumento populacional que impõe os limites da protoindústria, mas a dispersão produtiva e a incapacidade de gerar ganhos significativos de produtividade decorrentes da expansão extensiva da protoindústria. Também não há nada de contraditório em um elemento impulsionar a expansão e a retração de um sistema quando determinado limite é alcançado.

Especificamente sobre o crescimento populacional, Houston e Snell apontam várias regiões que tiveram grande aceleração do crescimento populacional dentro e fora da Inglaterra sem ter protoindústria concluindo que a protoindústria pode ter contribuído para o crescimento populacional em algumas áreas, mas não explica a tendência geral de aumento populacional no século XVIII.

Coleman (1983) fez a crítica mais contundente sobre a conexão entre protoindústria e aumento demográfico. Para o autor, não há estudos suficientes para comprovar que a protoindústria levaria ao crescimento populacional ou a casamentos mais cedo. Coleman indica trabalhos que apontam 
resultados contrários à teoria. Mesmo nos estudos em que foi encontrada uma idade mais jovem para os casamentos, como para o caso de Flandres estudado por Mendels, Coleman enfatiza que não foi possível distinguir o quanto do aumento populacional resultou de mudanças no padrão de casamento e o quanto resultou de migração. ${ }^{30}$ Uma versão mais leve da crítica de Coleman foi apresentada por Houston e Snell (1984) e Ogelvie (2008). Para esses autores, o crescimento demográfico é um fenômeno mais amplo que ultrapassa a dinâmica da protoindústria, e sua relação pode ser verificada para o Noroeste europeu, mas não para o Leste Europeu ou Japão. Vale notar que, no caso asiático, Huang (1990) encontrou uma relação positiva entre protoindústria e aumento populacional no Delta do Yangtzé na China.

Finalmente, o terceiro tópico é o conjunto de críticas à relação entre protoindustrialização e o surgimento da Revolução Industrial. Houton e Snell (1984) e Ogilvie (2008) argumentaram que, se a protoindústria era focada nos mercados externos, e há evidências de que os mercados externos não foram essenciais para a Revolução Industrial, então a protoindústria não teria sido essencial para a Revolução Industrial. Em resposta a essa crítica é possível apontar que a protoindústria também abastecia mercados internos, mas seria bom ir mais longe e contestar a afirmação de que os mercados externos foram irrelevantes para a industrialização. Recentemente, a ideia de que o mercado internacional foi muito relevante para a Revolução Industrial tem ganhado alguns importantes defensores. Esse é o caso de vários autores da chamada Escola da Califórnia de História Econômica. Por exemplo, Pomeranz (2001) apresenta estimativa de que o comércio intercontinental teria financiado $1 / 5$ a $1 / 6$ do investimento total na Europa no século XVIII.

Pomeranz também enfatiza que o algodão do novo mundo seria central para a produção europeia, que estava perto de uma "armadilha malthusiana" pela incapacidade de gerar por si própria as quatro "necessidades da vida", como teorizado por Thomas Malthus (1766-1834) (comida, fibra, combustível e material de construção). Todas as quatro necessidades da vida dependem da disponibilidade de terras, sendo muito difícil aumentar sua produção pelo uso mais intensivo de capital, dado o desenvolvimento tecnológico do período. Para Pomeranz (2001) a Europa não teria abundância de terras para gerar essas necessidades. Nesse sentido, as terras do Novo Mundo contribuiriam de maneira essencial para superar esse estran-

${ }^{30} \mathrm{O}$ que Mendels (1981) admite no seu trabalho embora acredite que isso não alteraria o resultado. 
gulamento. Assim, mesmo que o lucro do mercado das colônias não fosse alto para financiar o investimento, a matéria prima importada seria vital para o funcionamento do mercado europeu. ${ }^{31}$ Vale lembrar que KMS enfatizam que é necessária à produção protoindustrial para garantir o mercado colonial pelo lado da oferta. Para KMS isso ocorreria porque a indústria urbana, que era voltada para o mercado, seria insuficiente para absorver esse aumento de demanda como visto na seção 1. Sem a flexibilização da oferta europeia sustentada pela indústria rural, não seria possível atender os mercados externos. Assim, além de contestar que os mercados externos teriam pequena importância, podemos conectar protoindústria à formação do mercado colonial.

Finalmente, passamos para ao argumento de que haveria uma baixa correlação entre protoindústria e desenvolvimento industrial moderno. Os críticos apontam que a maioria das regiões protoindustriais não se desenvolveram conforme avançava a Revolução Industrial, mas se contraíram e se desindustrializaram. Esse ponto é colocado tanto por Coleman (1983) quanto Houston e Snell (1984) e Ogilvie (1993; 2008). No caso inglês, Coleman (1983) distingue dez regiões protoindústriais das quais somente quatro se industrializaram. ${ }^{32}$ Houston e Snell (1984) falam de desindustrialização na East Anglia, Kent, Sussex, partes de Lancashire, Cheshire, Normandia e outras partes da França, para citar somente alguns casos do Noroeste Europeu. ${ }^{33}$ Qual seria a força dessa teoria se o resultado mais comum é o inverso do que é previsto?

Reforçando esse ponto, Robert Allen (2000) apontou que a maior presença relativa ou absoluta de protoindústria não culminou em maior progresso para as nações europeias de modo geral. ${ }^{34} \mathrm{O}$ ponto de Allen é que a protoindústria estava razoavelmente disseminada na Europa e, no entanto, foi especificamente na Inglaterra que o crescimento se acelerou de forma diferenciada. Polônia e Império Austro-húngaro tinham relativamente mais protoindústria que a Inglaterra, enquanto França e Alemanha tinham prati-

${ }^{31}$ Pomeranz (2001) faz uma comparação interessante com o petróleo. O lucro no mercado de petróleo é pequeno se comparado ao lucro total nas economias contemporâneas, mas sem o petróleo não seria possível que uma série de atividades econômicas se realizasse. Da mesma forma a matéria prima das colônias na forma de comida e fibras seria essencial para o funcionamento do mercado europeu mesmo que o lucro nesse setor não fosse significativo frente ao total do mercado. Assim, a ênfase excessiva no lucro como única forma de contribuição para o crescimento econômico é enganadora.

32 São elas: West Yorshire, south Lanshire, south Yorkshire e West Midlands.

${ }^{33}$ Por outro lado, a presença de carvão e ferro levou ao desenvolvimento de indústria no Nordeste e Sul de Wales mesmo sem a presença precedente de protoindústria (Houston e Snell, 1984).

${ }^{34}$ Allen usou a população rural não agrícola como proxy para determinar o número de trabalhadores na protoindústria. 
camente a mesma quantidade relativa de protoindústria, então o tamanho relativo da protoindústria não parece ser um fenômeno determinante.

Sobre a presença absoluta da protoindústria, não há dúvida de que os países mais populosos se sobressaem sobre os menos populosos. França tinha quase duas vezes e meia mais protoindústria que a Inglaterra no fim do século XVIII, e essa proporção era ainda maior no fim do século XVII. Um exemplo fora da Europa é o caso da China que, em termos absolutos, tinha a maior produção protoindustrial e esta não levou ao desenvolvimento da indústria moderna nesse país (Allen 2000).

Se a protoindústria não era um fator determinante na industrialização, a pergunta necessária pode ser invertida: Por que os fatores apontados pela teoria protoindustrial não culminaram numa revolução industrial? Por que o capital acumulado, o empreendedorismo e conexões de mercado e o conhecimento técnico adquiridos na protoindustrialização não foram suficientes?

Para Coleman (1983), o principal desafio da indústria têxtil era a competição por preço e qualidade no mercado internacional. Como a protoindústria era menos propícia a inovação, ela não seria adequada para acompanhar o ritmo de modernização necessária. A protoindústria não garantia a existência de empreendedorismo e nem de capital necessário para induzir mudanças no método produtivo para enfrentar adequadamente a competição internacional. Ogilvie (2008) fala que o capital protoindustrial não fluiu somente para a indústria, mas para setores variados como agricultura e terras. Ogilvie também defende que a protoindústria era somente uma das fontes de conhecimento empreendedor na época e que muitas vezes esse conhecimento não chegou a ser criado.

Mokyr (1976) assim como Ogilvie (2008), enfatizou que o capital do comerciante protoindustrial foi somente uma das fontes de capital para a industrialização. Mokyr ainda ressalta que o custo de capital inicial para a industrialização era muito baixo e que não há evidência de que o capital dos comerciantes fosse necessário. ${ }^{35}$ Para Mokyr, o conhecimento em-

${ }^{35}$ Nesse aspecto, Mendels (1972) e KMS (1981) estariam de acordo com Mokyr, o capital para industrialização veio de muitas fontes e não somente da protoindústria. A questão seria o quão importante foi esse capital? Não há dados suficientes para dar uma resposta clara a essa pergunta. Chapman (1970) indica uma significativa presença do capital mercador nas primeiras indústrias têxteis, mas não especifica que esses mercadores e seu capital teriam vindo da protoindústria. De fato a protoindústria não era o foco do trabalho de Chapman, embora seu trabalho tenha sido indicado como prova da importância do capital mercador protoindustrial por KMS. 
preendedor gerado é um fator móvel e nada garante que ele tenha sido usado na região em que foi desenvolvido. Por último, Mokyr fala que o conhecimento técnico que os trabalhadores acumularam na protoindústria ajudou, mas não deve ser superestimado, pois a habilidade necessária para operar as máquinas era muito pequena, o que se verifica pelo "uso de mulheres e crianças" no trabalho. O grande desafio seria fazer a força de trabalho se acostumar com horas regulares, controle de qualidade, disciplina e relações não familiares. Nesses pontos a protoindústria não contribuiu.

Para Mokyr (1976), a principal maneira que a protoindústria contribuiu na industrialização foi como fonte de mão de obra. Houton e Snell (1984) são céticos nesse ponto. Segundo esses autores, os trabalhadores da protoindústria seriam antagônicos ao sistema de fábricas por razões culturais e econômicas. Houston e Snell vão além e defendem que as fábricas de tear modernas usaram mão de obra quase exclusivamente proveniente de fora da produção artesanal. Migrações muito localizadas e a separação de zonas protoindustriais e industriais modernas, em parte para fugir do ludismo, seriam provas dessa interpretação. KMS (1981) reconhecem que os trabalhadores protoindustriais tenderiam a resistir inicialmente ao sistema de fábricas, mas defendem que a necessidade de subsistência e a dificuldade de se organizar teriam quebrado a resistência desse grupo para trabalhar nas fábricas modernas.

Como apontado, a tese de que a protoindústria era uma percursora da industrialização moderna, que era a proposição original de Mendels, recebeu duras críticas na literatura econômica. No entanto, a extensão dessas críticas deixa de ser razoável ao não reconhecer que os autores da teoria sempre relativizaram essa proposição. Tanto KMS quanto Mendels sabiam que a protoindústria não era fator suficiente para a industrialização, o que esses autores sustentavam é que esse era um fator necessário e catalisador do processo. De fato, todos os países que se industrializaram passaram por uma fase protoindustrial, embora a distribuição regional de protoindústria e posterior indústria moderna não coincida em muitos casos.

Apesar das críticas, o conceito de protoindústria continuou a ter defensores aguerridos na literatura de história econômica. Entre esses, dois grupos se destacam. O primeiro grupo é liderado pela professora Sheilagh C. Ogilvie, que escreveu na última década obras importantes sobre o tema criticando o posicionamento anterior da teoria protoindustrial e defendendo uma revisão. Segundo a autora, a protoindústria foi um fenômeno muito diver- 
sificado, tendo características únicas em cada região, que só podem ser entendidas com estudos de caso e não com uma teoria ampla e homogênea como vinha até então sendo colocado (Ogilvie 2008).

O efeito da protoindústria também é diversificado, dependendo de inúmeras condições como disponibilidade de recursos, estrutura do mercado, regulamentação estatal, regras comunais, geografia, técnicas produtivas diversas, entre outras. Com tais premissas, Ogilvie desenvolveu uma linha de pesquisa com estudos detalhados de diversas regiões. Esse caminho também foi seguido por outros pesquisadores como Wolfgang Mager (1993), Belfanti (1993), Cerman (1993), os quais foram chamados por Ogilvie de "segunda geração de estudos sobre protoindústria". O que esses estudos apontaram foi que antes de se tornarem países industrializados no sentido moderno, a França já produzia tecidos de luxo dentro da protoindústria, a Inglaterra tecidos de linho e algodão dentro da protoindústria e a Suíça já fazia relógios dentro da protoindústria, ou seja, parte da futura especialização industrial destes países já estava colocada na produção protoindustrial. Ogilvie (2008) argumenta que é nessas singularidades que o estudo da protoindústria pode contribuir esclarecendo o caminho de desenvolvimento de cada país. Para isso, estudos mais regionais e empíricos e menos gerais e teóricos são necessários, o que Ogilvie defende que seria o papel da "segunda geração de estudos sobre protoindústria”.

Um segundo grupo de autores, que chamamos de "grupo clássico", continua defendendo a importância da protoindústria e vêm tentando resgatar os contornos originais da teoria. Em especial, o trabalho recente de Julie Marfany (2010) encontrou todos os preceitos clássicos da teoria protoindustrial na industrialização da Catalunha, a primeira região a se industrializar na Espanha. O aumento populacional, a transição para o sistema de fábrica, a localização geográfica da protoindústria, em suma, todos os aspectos batem com a teoria original. Marfany reconhece a crítica, mas continua defendendo que a correlação entre regiões que se industrializara e protoindústria é muito forte para que a teoria original seja abandonada. O que Marfany sustentou é que, pelo menos para algumas regiões, a teoria original continua com aderência e tem um forte poder explicativo. 


\section{Conclusão}

A tese de que o processo de protoindustrialização foi relevante para o surgimento da industrialização moderna ganhou corpo ao longo do tempo e enfrentou com êxito uma série de críticas que levaram à revisão dos seus conceitos. Sua versão mais acabada foi o resultado do trabalho das duas gerações de autores que trabalharam com essa hipótese. O grupo "clássico" que procurou defender a ideia original, ainda que sujeita a muitas críticas, e o grupo da "segunda geração", que procurou fazer estudos de caso muito diversificados, adicionou variáveis e trabalhou nas características regionais. Esse segundo grupo tem indicado áreas em que o desenvolvimento industrial seguiu o caminho apontado por Mendels e KMS, indicando que esses autores não estavam equivocados como alguns críticos apontaram. Assim, o poder heurístico da teoria continua significativo e ainda criou uma nova área de estudos com o desenvolvimento da Teoria da Protoindustrialização pela "segunda geração".

Como mencionado, a protoindústria foi um fenômeno amplo e não restrito à Europa, embora a teoria tenha se desenvolvido para tratar de um fenômeno observado nessa região. Outras grandes civilizações como a chinesa, a japonesa e o Império Otomano tiveram a presença da protoindústria e a compreensão desse fenômeno pode ser útil para além do continente europeu. Mesmo para o caso de economias coloniais como México e Brasil, no século XVIII, a protoindústria estava presente. Neste último caso, há amplo potencial não explorado para estudar a indústria rural usando conceitos propostos pela Teoria Protoindustrial. Finalmente, essa resenha mostra que em muitas regióes a protoindústria é um fenômeno que pode ser associado, em distintos graus, à indústria moderna. Nesse sentido, o instrumento teórico dessa abordagem ajuda a compreender as transformações na produção artesanal para mercado, tanto em casos de sucesso como nos muitos casos de fracasso da industrialização, em várias regiões do mundo. 


\section{Referências}

Allen, R. C. 2000. "Economic structure and agricultural productivity in Europe, 1300-1800.” European Review of Economic History 3: 1-25.

Belfanti, Carlo Marco. 1993. "Rural manufactures and rural proto-industries in the 'Italy of the Cities' from the sixteenth through the eighteenth century." Continuity and Change 8(2): 253-280, Agosto 1993.

Braverman, H. 1974. "Labor and Monopoly Capital”. Nova York: Monthly Review Press.

Braudel, Fernand. 2009. "Civilização material, economia e capitalismo: séculos XV-XVIII. Os jogos das trocas”. São Paulo: Martins Fontes.

Cameron, Rondo. 1985. “A New View of European Industrialization.” The Economic History Review 37(1), Fevereiro, 1985.

Cerman, Markus. 1993. "Proto-industrialization in an urban environment: Vienna, 1750-1857." Continuity and Change 8(2): 281-320, Agosto 1993.

Chapman, Stanley D. 1970. "Fixed Capital Formation in the British Cotton Industry, 1770-1815." The Economic History Review 23(2): 235-253, Agosto 1970.

Chayanov, A. V. 1966. “The theory of peasant economy”. Illinois: The American Economic Association.

Coleman, D. C. 1983. "Proto-Industrialization: A concept too many.” Economic History Review 36: 435-48.

Dantas, Mariana. 2008. "Black Townsmen: Urban Slavery and Freedom in the Eighteenth-Century Americas". New York: Palgrave Macmillan.

Dobb, M. 1967. “Studies in the Development of Capitalism”. Londres.

Grijalva, Mino. 1989. “Protoindustria Colonial?” Historia Mexicana 38(4), Abril-junho 1989.

Gullickson, Gay L. 1983. "Redefining the Causes of Proto-Industrialization." The Journal of Economic History 43 (4): 831-850.

Hicks, John. 1972. “Uma teoria de história econômica”. Rio de Janeiro: Zahar Editores.

Hobsbawm, Eric J. 2014. “A Era das Revoluções”. São Paulo, Paz e Terra, 2014.

Houston, Rab, Snell, D. D. M. 1984. "Proto-Industrialization? Cottage Industry, Social Change, and Industrial Revolution." The Historical Journal 27(2): 473-492, Junho 1984.

Huang, Philip C. C. 1990. "The Peasant Family and Rural Development in the Yangzi Delta, 1350-1988”. Stanford University Press.

Islamoglu-Inan, Huri. 1994. "State \& Peasant in the Ottoman Empire: Agrarian Power Relations \& Regional Economic Development in Ottoman Anatolia During the XVIth Century”. Nova York: E. J. BRILL.

Jeannin, Pierre. 1980. «La protoindustrialization: dévelippement ou impasse?» Annales. Économies, Sociétés, Civilisations, $35^{\mathrm{e}}$ année, 1: 52-65.

Jones, Eric L. 1968. «The agricultural origins of industry.» Past and Present 40:58-71.

Kiedte, P; Medick, H.; Schlumbohm, J. 1981. "Industrialization before industrialization”. Cambridge: Cambridge University Press.

Landes, S. 1969. "The Unbound Prometheus. Technological change and industrial development in Western Europe from 1750 to the present”. Cambridge: Cambridge University Press.

Levine, David. 1977. "Family formation in an age of nascent capitalism”. Nova York, Academic Press.

Mager, Wolfgang. 1993. "Proto-industrialization and proto-industry: the uses and drawbacks of two concepts." Continuity and Change 8(2): 181-215, Agosto 1993.

Marfany, Julie. 2010. "Is it still helpful to talk about proto-industrialization? Some suggestions from Catalan case study." The Economic History Review 63(4): 942-973. 
Marglin, Stephen. 1974. "What Do Bosses Do?: The Origins and Functions of Hierarchy in Capitalist Production." Review of Radical Political Economics 6 (60).

Marx, Karl. 1887. "O Capital. Crítica da economia Política.” Acessado em 30 de Junho 2009. https://www. marxists.org/archive/marx/works/download/pdf/Capital-Volume-I.pdf

Mendels, Franklin F. 1972. "The First Phase of the Industrialization Process.” The Journal of Economic History 32(1): 241-261, Março 1972.

. 1975. "Agriculture and Peasant Industry in Eighteenth-Century Flanders," In European Peasants and Their Markets. Editado por: N. Parker William e Eric L. Jones. Princeton.

Mokyr, Joel. 1976. "Growing-Up and the Industrial Revolution in Europe." Explorations in Economic History 13: 371-396.

Mokyr, Joel, Voth, Hans-Joachim. 2010. "Understanding growth in Europe, 1700-1870: theory and evidence." The Cambridge Economic History of Modern Europe 1: 1700-1870, editado por Stephan Broadberry e Kevin H. O'Rourke. Cambridge University Press.

Ogilvie, Sheilagh C. 1993. "Proto-industrialization in Europe." Continuity and Change 8(2): 159-179, Agosto 1993.

"Proto-industrialization." Acessado em 20 de Maio, 2008. http://www.econ.cam.ac.uk/people/faculty/ sco2/full-texts/Ogilvie-2008-Palgrave-proto-industrialization.pdf.

Pollard, Sidney. 1965. "The Genesis of Modern Management: A study of the industrial revolution in Great Britain". Cambridge: Harvard University Press. London.

Pomeranz, Kenneth. 2001. The Great Divergence China, Europe, and the Making of the Modern World Economy. New Jersey: Princeton University Press.

Thirsk, Joan. 1961. "Industries in the Countryside." Em Essays in the Economic and Social History of Tudor and Stuart England. Editado por F. J. Fisher. Cambridge.

Wallerstein, Immanuel. 2011. "The Modern World-System I. Capitalist Agriculture and The Origins of the European World-Economy in the Sixteenth Century”. Berkeley: University of California Press.

Wong, R. Bin. 1997. "China Transformed Historical Change and the Limites of European Experience". Cornell University Press. 